\title{
Electromagnetic Wave Shielding Effectiveness Based on Carbon Microcoil-Polyurethane Composites
}

\author{
Gi-Hwan Kang and Sung-Hoon Kim \\ Center for Green Fusion Technology, Department of Engineering in Energy \& Applied Chemistry, Silla University, \\ Busan 617-736, Republic of Korea \\ Correspondence should be addressed to Sung-Hoon Kim; shkim@silla.ac.kr
}

Received 4 April 2014; Revised 30 June 2014; Accepted 30 June 2014; Published 15 July 2014

Academic Editor: Antonios Kelarakis

Copyright (C) 2014 G.-H. Kang and S.-H. Kim. This is an open access article distributed under the Creative Commons Attribution License, which permits unrestricted use, distribution, and reproduction in any medium, provided the original work is properly cited.

Carbon microcoils (CMCs) were deposited onto $\mathrm{Al}_{2} \mathrm{O}_{3}$ substrates using $\mathrm{C}_{2} \mathrm{H}_{2} / \mathrm{H}_{2}$ as source gases and $\mathrm{SF}_{6}$ as an incorporated additive gas in a thermal chemical vapor deposition system. CMC-polyurethane (PU) composites were obtained by dispersing the CMCs in the PU with a dimethylformamide additive. The electromagnetic wave shielding properties of the CMC-PU composites were examined in the frequency range of $0.25-1.5 \mathrm{GHz}$. The shielding effectiveness (SE) of the CMCs-PU systematically increases with increasing the content of CMCs and/or the layer thickness. Based on these results, the main SE mechanism for this work was suggested and discussed.

\section{Introduction}

Recently, the importance of preventing electromagnetic interference (EMI) on diverse electronic equipment has increased with the rapid development of radiation sources and the high reliability requirements for electronic devices [1-3].

Absorption, reflection, and multiple reflections of EM radiation by the electronic components are regarded as the main shielding mechanisms for EMI [3-6]. For materials having high electric constants or magnetic permeability, absorption is known to be the major EMI shielding mechanism [3]. The absorption loss is a function known as $\sigma_{r} \mu_{r}$ ( $\sigma_{r}$ is the electrical conductivity relative to copper; $\mu_{r}$ is the relative permeability). For metals, the EMI reflection from the metal's free electrons is regarded as the major shielding mechanism $[3,4]$, usually requiring an interaction between the mobile charge carriers and the electromagnetic fields in the radiation. Consequently, the shield tends to be electrically conducting, although it does not need a complete connection in the conduction path [5]. In comparison, the reflection loss is a function of $\sigma_{r} / \mu_{r}$. In general, the reflection loss decreases with increasing frequency, whereas the absorption loss increases with increasing frequency [6]. Additionally, the reflection loss is independent of the shield thickness, while the absorption loss is proportional to the thickness of the shield [6]. Meanwhile, the multiple reflections caused by interfaces and/or the various surfaces of the shielding materials are regarded as another primary EMI shielding mechanism. This mechanism requires a large surface or interface area, such as a composite material containing fillers. Fu and Chung reported that small fillers with high surface areas in a composite gave rise to enhanced shielding performance owing to the skin effect, namely, the interaction of highfrequency radiation with only the surface of the materials [7].

Up to the present, metals have been commonly used as EMI shielding materials in the $0.5-2.0 \mathrm{GHz}$ range for mobile phones. Owing to the increasing demand for lightweight and moldable materials, polymer-matrix composites for use as EMI shielding materials are strongly desired for portable electronic devices, avionic electronics, and so forth, $[7,8]$. In this respect, carbon materials (including carbon fibers, carbon nanotubes, carbon blacks, carbon coils, graphites, etc.) have been seen as promising candidates for EMI shielding materials [9-13]. In particular, carbon microcoils (CMCs), which have DNA-like double helix geometry, are appealing as electromagnetic wave absorbers because they appear to 
TABLE 1

\begin{tabular}{|c|c|c|c|c|c|c|c|c|}
\hline \multirow[t]{2}{*}{$\begin{array}{l}\mathrm{C}_{2} \mathrm{H}_{2} \text { flow rate } \\
(\mathrm{sccm})\end{array}$} & \multirow[t]{2}{*}{$\begin{array}{c}\mathrm{H}_{2} \text { flow rate } \\
(\mathrm{sccm})\end{array}$} & \multirow[t]{2}{*}{$\begin{array}{l}\mathrm{SF}_{6} \text { flow rate } \\
(\mathrm{sccm})\end{array}$} & \multirow[t]{2}{*}{$\begin{array}{l}\text { Total pressure } \\
\text { (Torr) }\end{array}$} & \multirow[t]{2}{*}{$\begin{array}{l}\text { Total deposition time } \\
\text { (min) }\end{array}$} & \multicolumn{3}{|c|}{$\begin{array}{l}\text { Source gases flow time } \\
(\mathrm{min})\end{array}$} & \multirow{2}{*}{$\begin{array}{l}\text { Substrate temp. } \\
\qquad\left({ }^{\circ} \mathrm{C}\right)\end{array}$} \\
\hline & & & & & $\mathrm{C}_{2} \mathrm{H}_{2}$ & $\mathrm{H}_{2}$ & $\mathrm{SF}_{6}$ & \\
\hline 15 & 35 & 35 & 100 & 90 & 90 & 90 & 5 & 750 \\
\hline
\end{tabular}

TABLE 2

\begin{tabular}{lccc}
\hline Samples & \multicolumn{3}{c}{ Weight \% } \\
& CMCs & PU & DMF \\
\hline Sample A & 4.1 & 67.6 & 28.3 \\
Sample B & 11.3 & 68.8 & 19.9 \\
Sample C & 16.7 & 66.1 & 17.2 \\
\hline
\end{tabular}

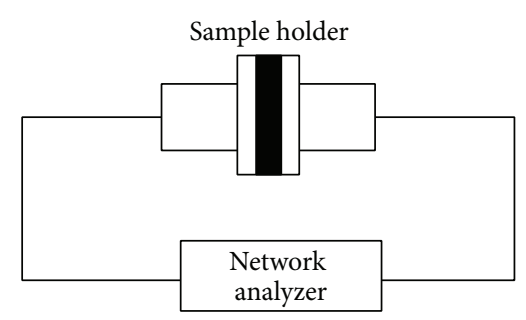

FIGURE 1: The instrumental setup for measuring shielding effectiveness.

induce an electrical current, consequently generating a magnetic field $[12,13]$. Indeed, the coil geometry was understood to be an effective form for inducing current through an inductive electromotive force, unlike that of the straight- or powder-like forms.

Unfortunately, the geometries of the carbon coils were diverse in the as-grown state. Additionally, their diameter could vary from the nanometer to the micrometer scale. Indeed, the electrical properties of the helically coiled CMCs can have considerable geometry-dependent variation, similar to that of straight carbon nanotubes [14]. Therefore, it would be indispensable to be able to control the geometry (diameter, pitch, length, and turning direction) of the carbon coils for their application as electromagnetic wave absorbers.

Previously, we reported that the injection of $\mathrm{SF}_{6}$ gas during the initial reaction stage was effective on controlling the geometry of the formed CMCs [15-17]. In this work, we obtained the geometrically controlled CMCs using the $\mathrm{SF}_{6}$ additive and then formed CMC-polyurethane (PU) composites by dispersing the CMCs in the PU with a dimethylformamide (DMF) additive. Polymethyl methacrylate [12] and paraffin wax [13] have been reported for the polymer matrix of carbon coils. In this work, however, we chose PU for the matrix because it is more readily available. The EM wave shielding properties of the CMC-PU composites were examined according to the weight percent of the CMCs in the $\mathrm{PU}$ and the composite layer thickness across the frequency range of $0.25-1.5 \mathrm{GHz}$. Based on these results, we determined the main shielding mechanism for the CMC-PU composites.

\section{Experimental}

For the carbon coil deposition, a thermal chemical vapor deposition (TCVD) system was employed. $\mathrm{C}_{2} \mathrm{H}_{2}$ and $\mathrm{H}_{2}$ were used as the source gases, and $\mathrm{SF}_{6}$, an incorporated additive gas, was injected into the reactor during the reaction. The flow rate for $\mathrm{C}_{2} \mathrm{H}_{2}, \mathrm{H}_{2}$, and $\mathrm{SF}_{6}$ was fixed at 15,35 , and 35 standard $\mathrm{cm}^{3}$ per minute $(\mathrm{sccm})$, respectively. Table 1 shows the detailed reaction conditions for the CMC deposition. The detailed morphologies of the as-grown carbon coils were investigated using field emission scanning electron microscopy (FESEM).

For the CMC-PU composites, the CMCs were dispersed in the PU with the addition of DMF using an ultrasonic system. The range of PU molecular weight in this work was $60,000 \sim 70,000$. After $120 \mathrm{~min}$ of on/off ultrasonic treatment at $500 \mathrm{~W}$ and $20 \mathrm{kHz}$, a paste-type CMC-PU-DMF mixture was obtained. We prepared three kinds of samples (samples $\mathrm{A}, \mathrm{B}$, and $\mathrm{C}$ ) having different $\mathrm{CMC}$ composition ratios in the paste-type CMC-PU-DMF mixtures as shown in Table 2. After manufacturing the three kinds of paste-type samples, each sample was coated onto a circular-shaped glass plate $133 \mathrm{~mm}$ in diameter. For the coating, about $20 \mathrm{~mL}$ of the paste-type sample was poured onto the glass plate, and then the coated samples were dried naturally in a fume hood for about 24 hours. Finally, the weight of the coated samples was measured using an electronic balance (BJ210s, Sartorius).

For the electrical resistivity measurements, we fabricated square CMC-PU sheets having dimensions of 40 (length) $\times$ 35 (width) $\mathrm{mm}$. For the coating, about $2 \mathrm{~mL}$ of the pastetype samples was poured onto the sheet, and then the coated sheets were naturally dried in the fume hood for 24 hours. The volume resistivity $(\Omega \mathrm{cm})$ of the sheets was measured by fourpoint probe (labsysstc-400, Nextron) using Ohm's law and a correction factor at room temperature [18].

The SE of the CMC-PU composites was analyzed using a network analyzer (SynthNV2_3b, Windfreak Tech.) in accordance with ASTM D4935-99. The setup consisted of a sample holder with its outside connected to the network analyzer (see Figure 1). The coaxial sample holder (Electro Matrix EM2107A) and the coaxial transmission test specimen were set according to ASTM D4935-99 as shown in Figure 2. The performance measurement range of the SE for the CMC-PU composites was from $250 \mathrm{MHz}$ to $1.5 \mathrm{GHz}$.

\section{Results and Discussion}

Figure 3 shows the FESEM images of the substrate surface morphologies for samples produced by the continuous $\mathrm{C}_{2} \mathrm{H}_{2}$ $+\mathrm{H}_{2}$ flow process with $5 \mathrm{~min}$ of $\mathrm{SF}_{6}$ gas flow addition during the initial reaction. Figures $3(\mathrm{~b})$ and $3(\mathrm{c})$ show the magnified 


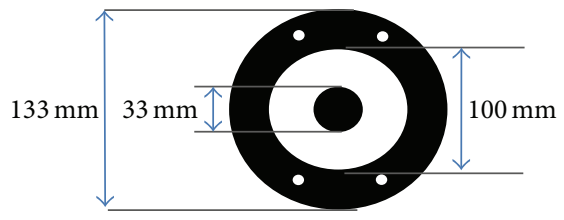

Reference

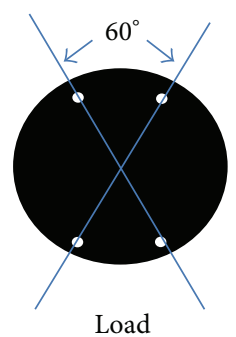

Load

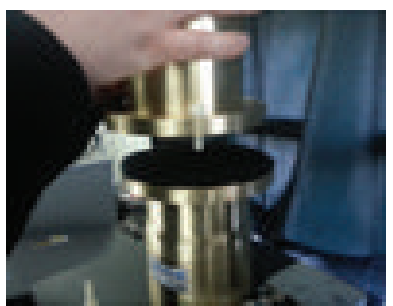

(b)

FIGURE 2: (a) The coaxial transmission test specimen adhering to ASTM D4935-99 and (b) the coaxial sample holder.

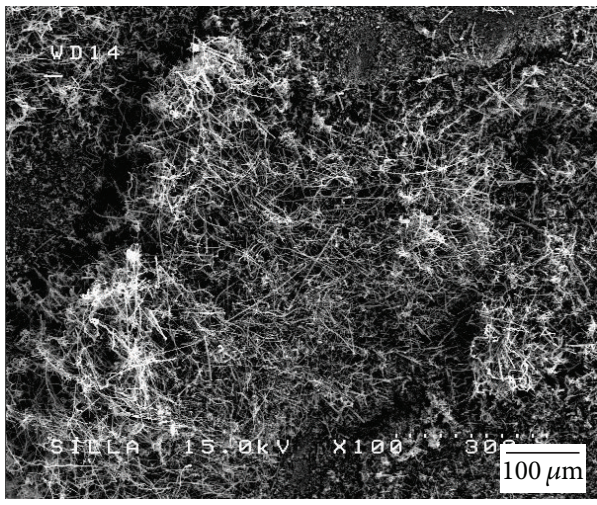

(a)

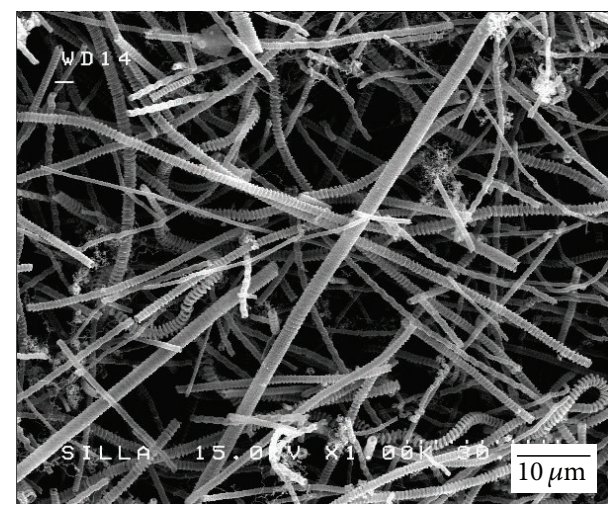

(b)

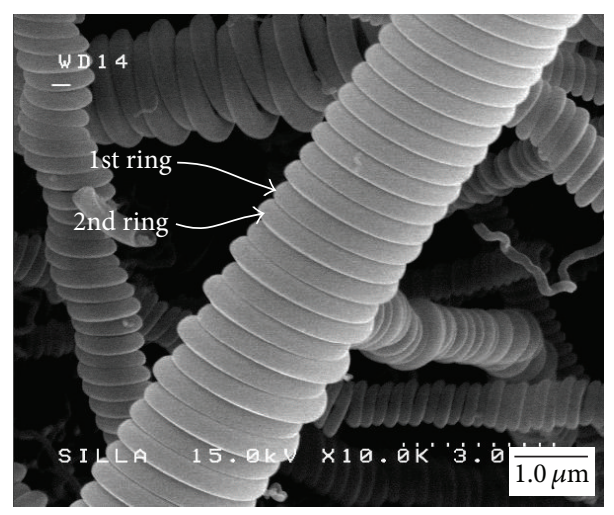

(c)

FIGURE 3: The representative FESEM images of the substrate surface morphologies produced using the continuous $\mathrm{C}_{2} \mathrm{H}_{2}+\mathrm{H}_{2}$ flow process with 5.0 min of $\mathrm{SF}_{6}$ gas flow addition during the initial reaction process. (a) The formation of carbon microfilaments on the entire surface area of the sample, (b) the magnified (1 k) image of Figure 1(a), and (c) the highly magnified (10 k) image of Figure 1(b).

images of Figures 3(a) and 3(b), respectively. As shown in these figures, the well-structured CMCs were prevalent on the surface on the sample. These results reveal that the continuous $\mathrm{C}_{2} \mathrm{H}_{2}+\mathrm{H}_{2}$ flow process with the 5 min of $\mathrm{SF}_{6}$ gas flow addition during the initial reaction can give rise to the dominant form of the CMCs. As shown in Figure 3(c), the first and second rings of the CMCs are clearly observed, indicating that the formation of the CMCs in this work follows the typical double-helix geometry for the structure. For the shape of the rings constituting the coils, circular-type morphology was observed.
Figure 4(a) shows a representative photograph of the coated paste-type CMC-PU-DMF mixture on the glass plate. Figure 4(b) shows a representative cross-sectional FESEM image of the coated samples after the natural drying process. As shown in Figure 4(b), the existence of the CMCs in the coated layers could be clearly observed. The weight variation for the coated layers of the different samples was measured as a function of the number of coatings. The time intervals between the coatings were approximately 24 hours. As shown in Figure 5, the weight of the coated layers gradually increased with the number of coatings. Although we poured almost 


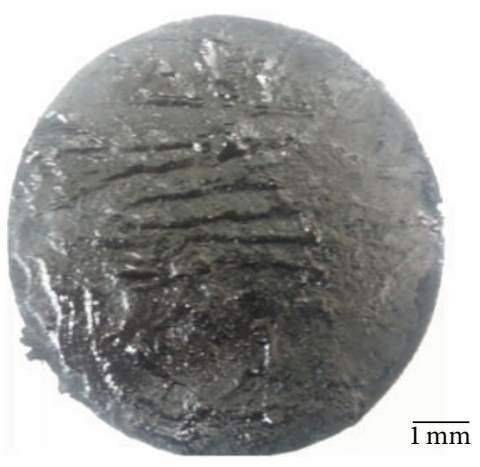

(a)

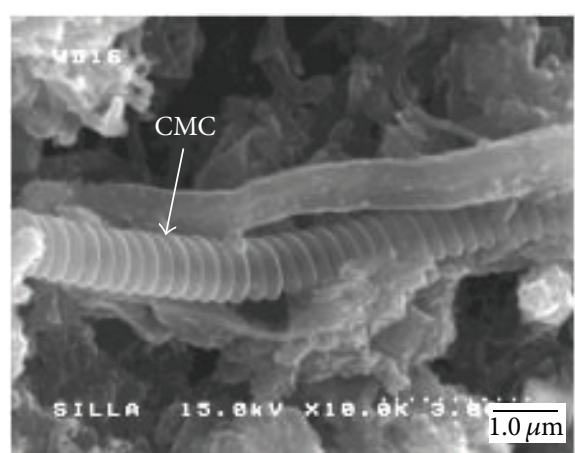

(b)

FIGURE 4: (a) The representative photograph of the coated layer surface on the glass plate and (b) the cross-sectional FESEM image of the coated layer showing the existence of CMCs within the PU-CMC composite.

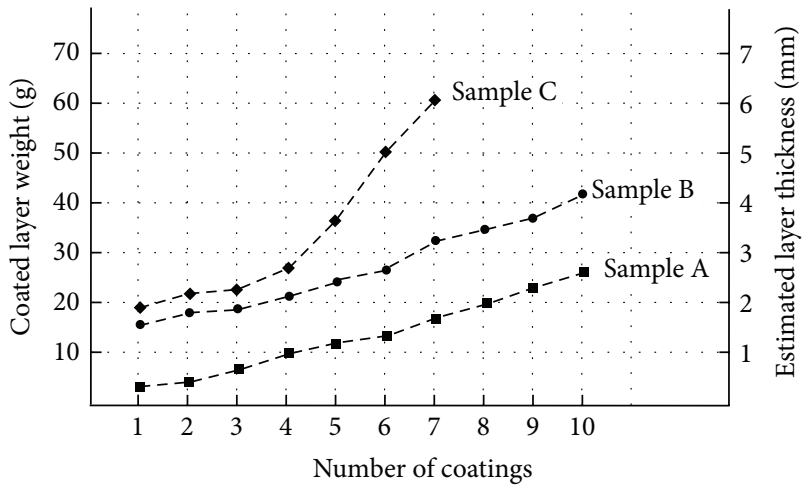

FIGURE 5: The variation of the coated layer weights for the different samples, with the estimated layer thickness as a function of the number of coatings.

the same amount $(\sim 20 \mathrm{~mL})$ of the paste-type sample for every coating, the increased weight of the coated layers of the samples was not directly proportional to the number of coatings. This was due to the volatile DMF, which evaporated during the natural drying process. As expected, sample $\mathrm{C}$, having the highest composition ratio of CMCs in the CMC-PU-DMF mixture, gave rise to the highest weight of the coated layers among the samples, irrespective of the number of coatings. For the thickness of the coated layers, we estimated that the proportional ratio for the layers' weight $(\mathrm{g})$, to the layer thickness $(\mathrm{mm})$, was approximately 10 , although the thickness of the coated layers might be uneven at different locations on the sample. This estimation was carried out by the comparison between the cross-sectional FESEM image of a certain point of the sample and the weight of the sample.

After measuring the weights of the coated layers on the samples, we examined the volume resistivity dependence of the CMC-PU sheets relative to the number of coatings as shown in Figure 6. The sheet corresponding to sample C has the lowest volume resistivity among the sheets under similar thicknesses (see Figure 6 and the inset in Figure 6).

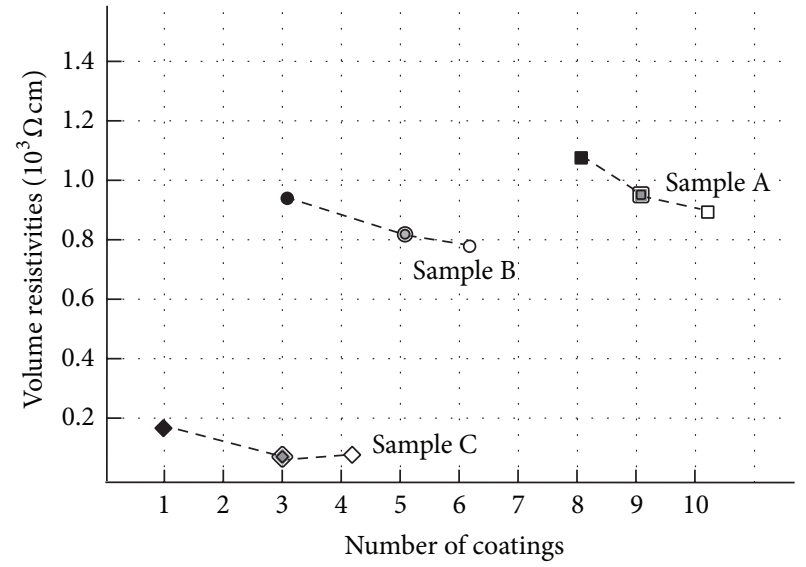

Sheet thickness

$$
\begin{array}{ll}
\text { 口, } & \sim 2.0 \mathrm{~mm} \\
\text { 回, ○, } \sim & \sim 2.5 \mathrm{~mm} \\
\text {, }, \diamond, \diamond & \sim 2.8 \mathrm{~mm}
\end{array}
$$

FIGURE 6: The dependence of the PU-CMC sheet volume resistivity relative to the number of coatings.

As expected, the higher amount of CMCs in the PU-CMCDMF mixture, the higher the electrical conductivity of final CMC-PU sheet.

Considering only the reflection and the absorption effects as the main shielding mechanisms for the EM interference of this work, the SE of the EM interference for the electrically conductive polymer composites can be estimated by the empirical equation of Simon [19]:

$$
\mathrm{SE}=50+10 \log _{10}(\rho f)^{-1}+1.7 t(f / \rho)^{1 / 2},
$$

where $\mathrm{SE}$ is in $\mathrm{dB}, \rho$ is the volume resistivity $(\Omega \mathrm{cm})$ at room temperature, $t$ is the thickness of the sample $(\mathrm{cm})$, and $f$ is the measurement frequency, respectively. Indeed, the multiple reflections effect, likely significant in the nanoscale filler system, was thought to be minimized in this work because we used only micron-sized carbon coils. In the previous equation, the combined first and second terms, namely, 


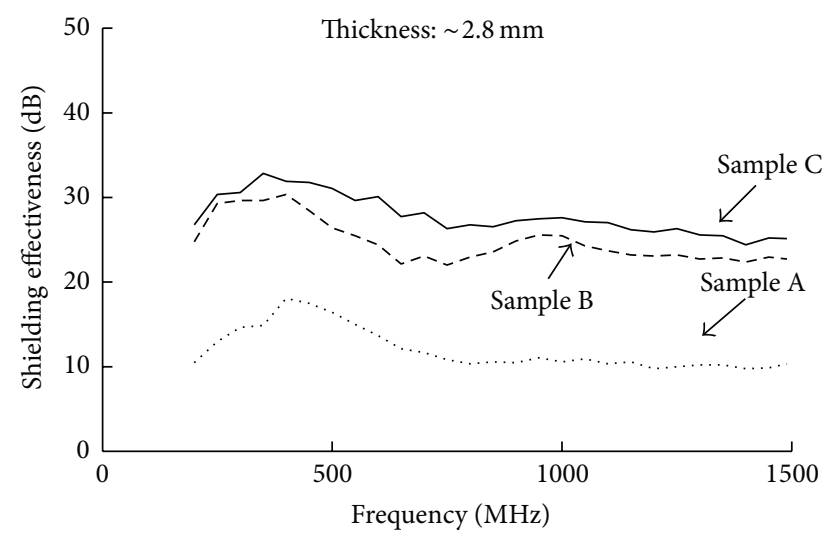

FIgURE 7: The variation of shielding effectiveness relative to the different composition ratios of the CMCs in the CMC-PU-DMF mixture.

$50+10 \log _{10}(\rho f)^{-1}$, show only the reflection mechanism SE. The third term, namely, $1.7 t(f / \rho)^{1 / 2}$, indicates only the absorption mechanism SE. As indicated by this equation, the $\mathrm{SE}$ from the reflection decreases with increasing measurement frequency, while the SE from the absorption increases with increasing measurement frequency. For the composite layer thickness dependence, only the SE from the absorption mechanism increases with increasing thickness $(t)$.

For the SE measurement, we investigated the SE variation compared to the different $\mathrm{CMC}$ composition ratios in the CMC-PU-DMF mixture (see Figure 7) and the different thicknesses of the composite (see Figure 8). As shown in Figure 7, we compared the SE of the CMC-PU composites for samples A-C under similar composite layer thicknesses. Sample C, with the highest electrical conductivity of the CMC-PU composites in this work, also has the highest SE among the samples. This indicates that the reflection effect may work as the dominant SE mechanism for the EMI in these composites. However, the combined result of Figures 6 and 7 shows that the increase in the SE is not directly proportional to the volume resistivity increase. Accordingly, this result strongly informs us that the other mechanisms besides reflection, namely, the absorption effect, will play a critical role as the SE mechanism for the EMI of these composites. Measuring the frequency dependence of the SE for these composites, we could not confirm any variation of the SE with the frequency. However, we are convinced that the SE did not decrease with increasing measurement frequency in the range of $1.0 \mathrm{GHz}$ to $1.5 \mathrm{GHz}$. This result also reveals that the main EMI mechanism in these composites is not the reflection effect. Furthermore, Figure 8 clearly reveals that the SE increases with an increase of the coated layer thickness, clearly indicating that the absorption mechanism is the composite's main EMI mechanism in this work.

As shown in Figure 8, for Sample B, layers with thicknesses greater than $2.0 \mathrm{~mm}$ show a SE above $20 \mathrm{~dB}$, demonstrating that more than $99 \%$ of the injected electromagnetic waves have been shielded. Even from the industrial point of view, this value is considered sufficient for use across numerous application fields. As the previous reports, CMCs,

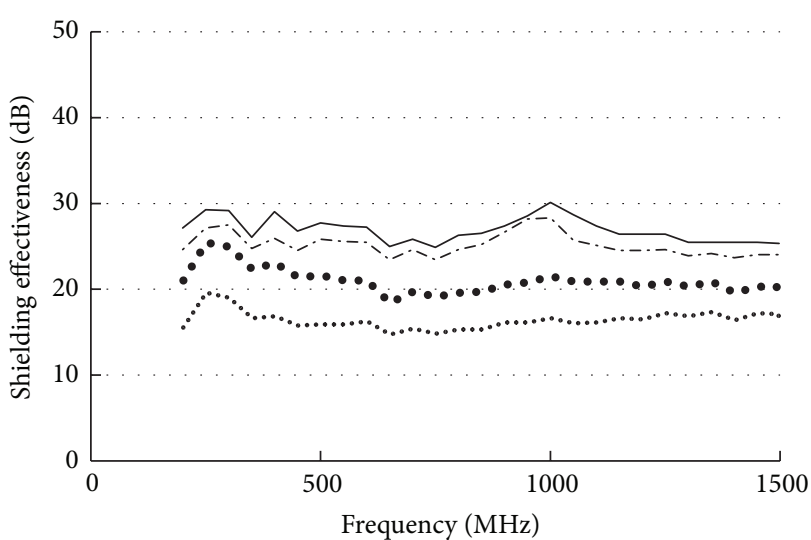

$$
\begin{aligned}
& \text { Layer thickness of sample B }
\end{aligned}
$$

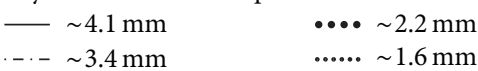

Figure 8: The variation of shielding effectiveness for sample B relative to the different thicknesses of the coated layers.

associated with the absorption mechanism of the SE, would be useful mainly in the relatively high frequency (above several GHz) region $[12,13]$. However, this work confirms that the CMC-PU composite will be applicable even in the mobile communication region (around 1 2 GHz).

\section{Conclusions}

The highest electrical conductivity of the PU-CMC composites in this work corresponds to the highest $\mathrm{SE}$ among samples under similar coated layer thicknesses. However, the increase of the SE is not directly proportional to the increase of the volume resistivity. Additionally, the SE did not decrease with increasing measurement frequency in the range of $1.0 \mathrm{GHz}$ to 1.5 GHz. Furthermore, the SE increases with an increase of the composite layer thickness. Based on these results, we confirm that the main EMI mechanism for the composites in this work is the absorption mechanism.

\section{Conflict of Interests}

The authors declare that there is no conflict of interests regarding the publication of this paper.

\section{Acknowledgments}

This research was supported by the Basic Science Research Program through the National Research Foundation of Korea (NRF) funded by the Ministry of Education, Science and Technology (2013R1A1A2007157).

\section{References}

[1] D. D. L. Chung, "Materials for electromagnetic interference shielding," Journal of Materials Engineering and Performance, vol. 9, no. 3, pp. 350-354, 2000. 
[2] K. Lozano, "Vapor-grown carbon-fiber composites: processing and electrostatic dissipative applications," The Journal of Minerals, Metals \& Materials Society, vol. 52, no. 11, pp. 34-36, 2000.

[3] D. D. L. Chung, "Electromagnetic interference shielding effectiveness of carbon materials," Carbon, vol. 39, no. 2, pp. 279-285, 2001.

[4] J. Wu and D. D. L. Chung, "Increasing the electromagnetic interference shielding effectiveness of carbon fiber polymermatrix composite by using activated carbon fibers," Carbon, vol. 40, no. 3, pp. 445-447, 2002.

[5] K. P. Sau, T. K. Chaki, A. Chakraborty, and D. Khastgir, "Electromagnetic interference shielding by carbon black and carbon fibre filled rubber composites," Plastics, Rubber and Composites Processing and Applications, vol. 26, no. 7, pp. 291297, 1997.

[6] S. Yang, K. Lozano, A. Lomeli, H. D. Foltz, and R. Jones, "Electromagnetic interference shielding effectiveness of carbon nanofiber/LCP composites," Composites A: Applied Science and Manufacturing, vol. 36, no. 5, pp. 691-697, 2005.

[7] X. Fu and D. D. L. Chung, "Submicron carbon filament cementmatrix composites for electromagnetic interference shielding," Cement and Concrete Research, vol. 26, no. 10, pp. 1467-1472, 1996.

[8] J. Wu and D. D. L. Chung, "Improving colloidal graphite for electromagnetic interference shielding using $0.1 \mu \mathrm{m}$ diameter carbon filaments," Carbon, vol. 41, no. 6, pp. 1313-1315, 2003.

[9] X. Luo, R. Chugh, B. C. Biller, Y. M. Hoi, and D. D. L. Chung, "Electronic applications of flexible graphite," Journal of Electronic Materials, vol. 31, no. 5, pp. 535-544, 2002.

[10] X. Luo and D. D. L. Chung, "Electromagnetic interference shielding using continuous carbon-fiber carbon-matrix and polymer-matrix composites," Composites B: Engineering, vol. 30, no. 3, pp. 227-231, 1999.

[11] N. C. Das, D. Khastgir, T. K. Chaki, and A. Chakraborty, "Electromagnetic interference shielding effectiveness of carbon black and carbon fibre filled EVA and NR based composites," Composites A, vol. 31, no. 10, pp. 1069-1081, 2000.

[12] S. Motojima, S. Hoshiya, and Y. Hishikawa, "Electromagnetic wave absorption properties of carbon microcoils/PMMA composite beads in W bands," Carbon, vol. 41, no. 13, pp. 2658-2660, 2003.

[13] D. Zhao and Z. Shen, "Preparation and microwave absorption properties of carbon nanocoils," Materials Letters, vol. 62, no. 21-22, pp. 3704-3706, 2008.

[14] K. Akagi, R. Tamura, M. Tsukada, S. Itoh, and S. Ihara, "Electronic structure of helically coiled cage of graphitic carbon," Physical Review Letters, vol. 74, no. 12, pp. 2307-2310, 1995.

[15] J.-H. Eum, S.-H. Kim, S. S. Yi, and K. Jang, "Large-scale synthesis of the controlled-geometry carbon coils by the manipulation of the $\mathrm{SF}_{6}$ gas flow injection time," Journal of Nanoscience and Nanotechnology, vol. 12, no. 5, pp. 4397-4402, 2012.

[16] J. Eum, Y. Jeon, and S. Kim, "Effect of gas phase composition cycling on/off modulation numbers of $\mathrm{C}_{2} \mathrm{H}_{2} / \mathrm{SF}_{6}$ flows on the formation of geometrically controlled carbon coils," Journal of Nanoscience and Nanotechnology, vol. 12, no. 7, pp. 6100-6106, 2012.

[17] Y.-C. Jeon, J.-H. Eum, S.-H. Kim, J.-C. Park, and S. I. Ahn, "Effect of the on/off cycling modulation time ratio of $\mathrm{C}_{2} \mathrm{H}_{2} / \mathrm{SF}_{6}$ flows on the formation of geometrically controlled carbon coils," Journal of Nanomaterials, vol. 2012, Article ID 908961, 6 pages, 2012.
[18] F. Smits, "Measurement of sheet resistivities with the four-point probe," Bell System Technical Journal, vol. 37, pp. 711-717, 1958.

[19] R. M. Simon, "EMI shielding through conductive plastics," Polymer-Plastics Technology and Engineering, vol. 17, no. 1, pp. 1-10, 1981. 

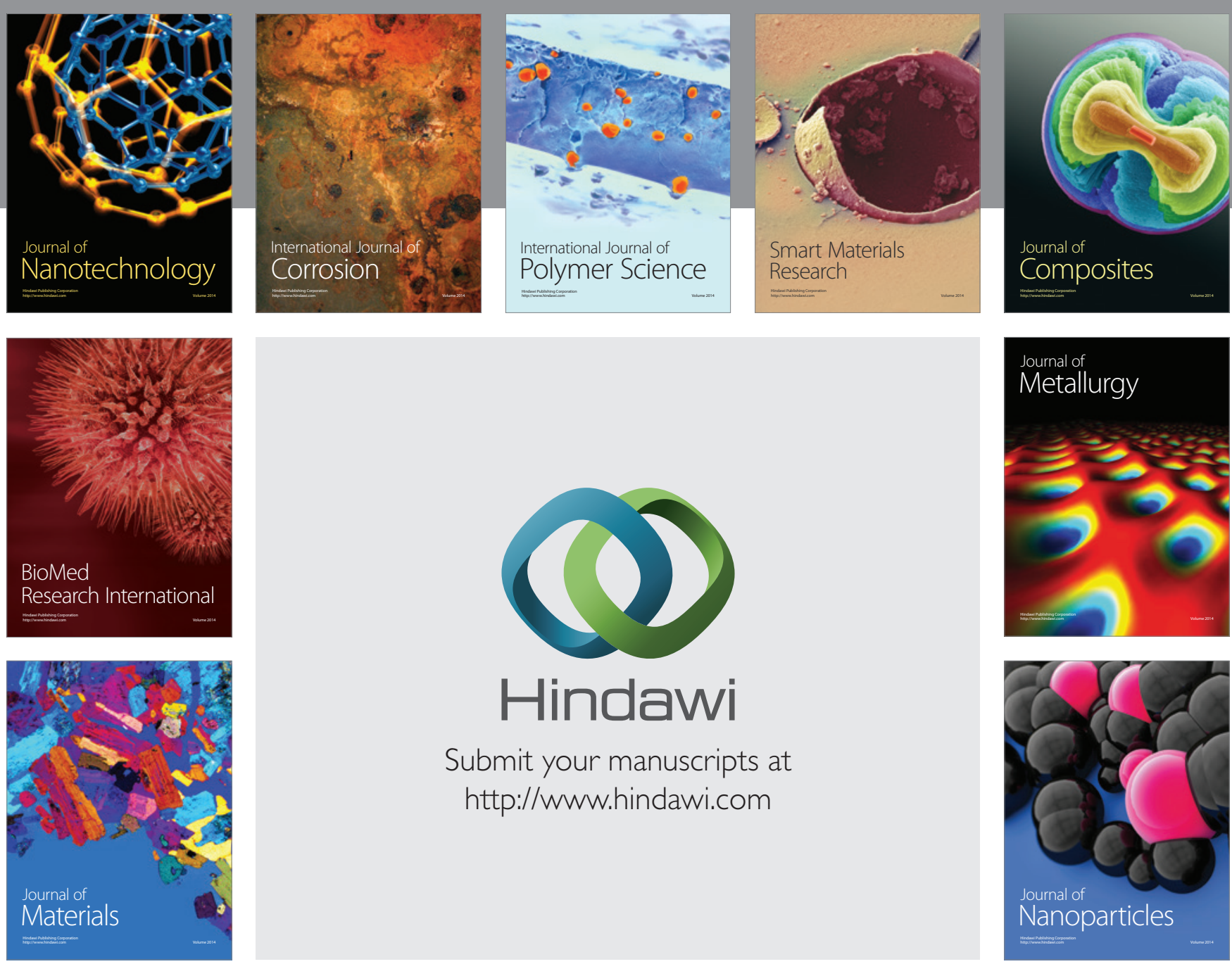

Submit your manuscripts at http://www.hindawi.com
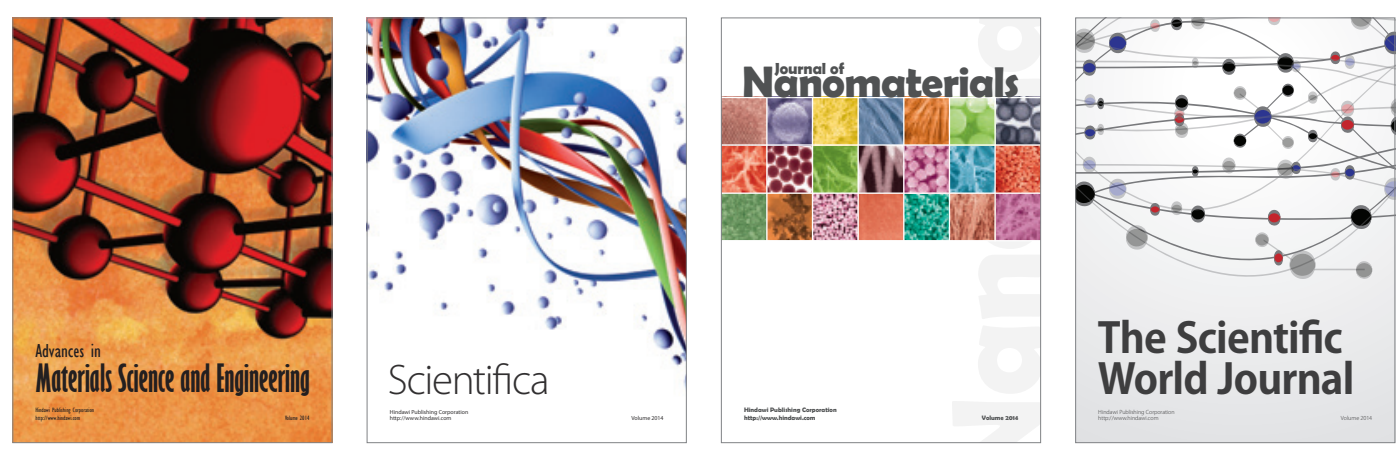

\section{The Scientific World Journal}
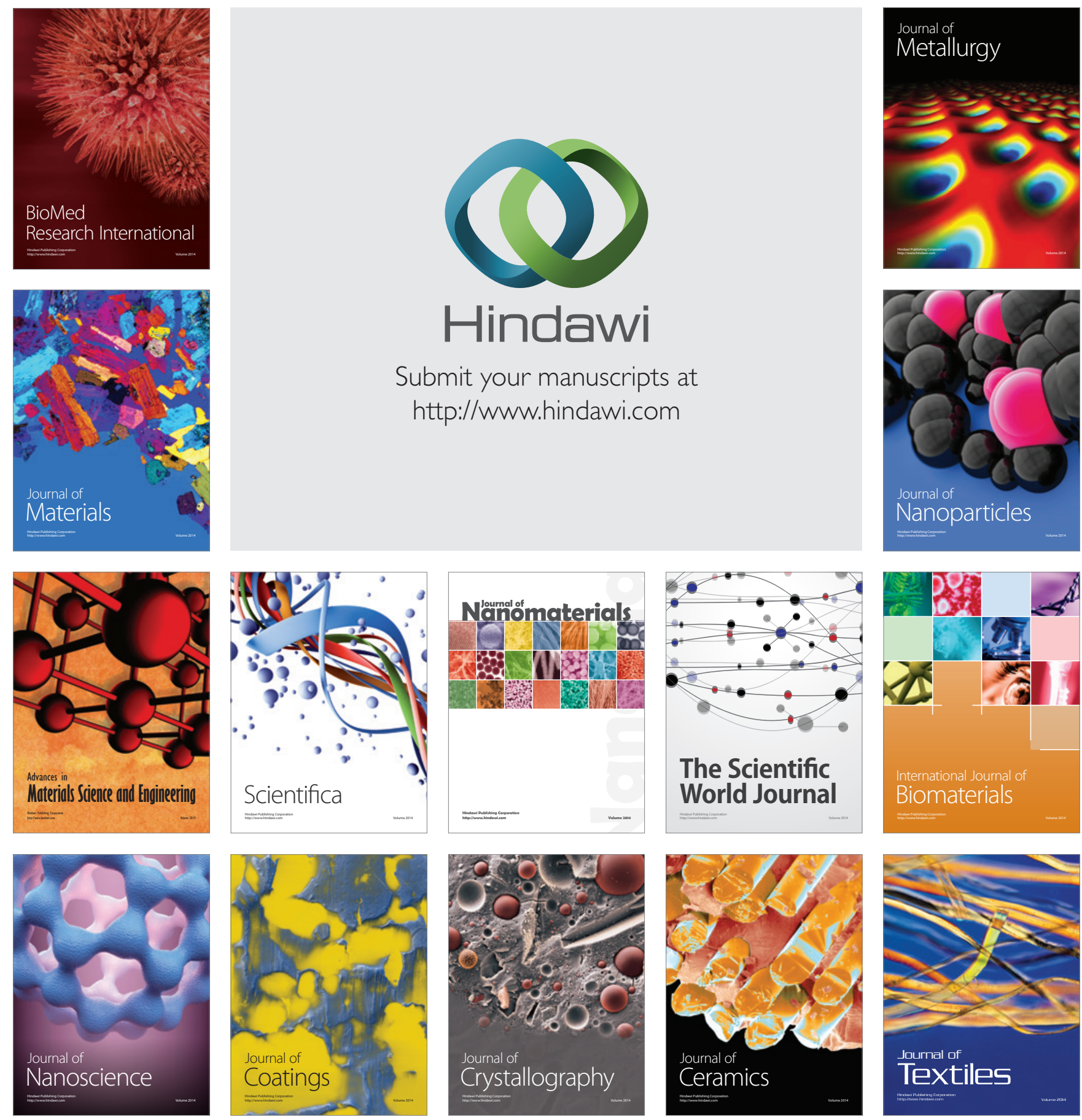